\title{
Research Initiatives in Europe
}

\author{
Nicola Robinson ${ }^{\mathrm{a}} \quad$ Corina Güthlin $^{\mathrm{b}} \quad$ Wolfgang Weidenhammer $^{\mathrm{c}} \quad$ Ursula Wolf $^{\mathrm{d}}$ \\ ${ }^{a}$ Centre for Complementary Healthcare and Integrated Medicine (CCHIM), Faculty of Health and Human Sciences, \\ Thames Valley University, Brentford, United Kingdom \\ ${ }^{\mathrm{b}}$ Institute for General Practice, Johann Wolfgang Goethe University, Frankfurt/M., Germany \\ ${ }^{\mathrm{c}}$ Kompetenzzentrum für Komplementärmedizin und Naturheilkunde, Klinikum rechts der Isar, TU München, Germany \\ ${ }^{d}$ Institute of Complementary Medicine KIKOM, University of Bern, Switzerland
}

\section{The European Chapter of the International Society for Complementary Medicine Research}

On November 8, 2008 the 'European Chapter' of the 'International Society for Complementary Medicine Research' (ISCMR) was established. It was launched at the first European Congress for Integrative Medicine (ECIM) in Berlin 2008, and since then, 2 annual meetings have been held (November 2009, ECIM, Berlin, and May 2010, ISCMR, Troms $\varnothing$, Norway).

The European Chapter is the first regional group under the umbrella of the ISCMR. It constitutes a platform for researchers involved in complementary medicine, and promotes exchange and cooperation within Europe. The European Chapter regularly informs its members about CAM-related activities in Europe, which are of interest to researchers, and meets regularly within general assemblies in order to discuss topics such as education or the European Union Research Framework Programmes. More information can be found in the near future when www.iscmr.org will be fully operational.

The European Chapter steering group consists of: Nicky Robinson (chair), Ursula Wolf (co-chair), Wolfgang Weidenhammer, and Corina Güthlin. The next meeting of the Chapter will take place during the ECIM 2011 (www.ecimcongress.org/).

\section{European CAM Research Network}

One of the major aims of the European Chapter is to build up and foster a network of European research groups in the field of CAM. This task is currently being facilitated by the EUFP7 funded coordination project CAMbrella (www.cambrella. $e u$ ) which was established at the beginning of 2010. It cur- rently consists of 16 university-based academic research institutions from 12 European member states. Overall goals of this 3 -year coordination project are to describe the regulation and clinical provision of CAM in the European Union and to develop a roadmap for future CAM research that is appropriate to the healthcare needs of EU citizens. Once the roadmap is designed, CAMbrella could act as a nucleus for future CAM collaborations within the European Chapter platform.

\section{EU Grants for Future Research Projects}

The recent successful inclusion of a CAM topic in the FP7 Health Work Programme is fuelling hopes for further research projects funded by the 7 th or the subsequent 8 th Framework Programme (FP). In 2009, the European Chapter established a working group whose members (Paolo Roberti di Sarsina, Nicky Robinson, George Lewith, Seamus Connolly, Corina Guethlin, Wolfgang Weidenhammer) to discuss how best to prepare the European CAM research community for future projects. The European Commission has opened the discussion on FP8 (2014-2020) also addressing potential priorities of the Europe 2020 strategy. The overall economic situation may, however, have an impact on the budgetary negotiations for FP8. Some countries (e.g., Austria, UK) have initiated consultation processes to gather researchers' views in order to improve European research funding. The network of National Contact Points (NCP) provides support for EU grants and plays an important role in lobbying CAM projects. The German NCP, for example, regularly collects proposals for research topics for consideration in upcoming calls. The European Chapter's working group tries to coordinate and provide help for appropriate and promising activities by using the multinational network.

\section{KARGER}

Fax +497614520714

Information@Karger.de

www.karger.com (c) 2010 S. Karger GmbH, Freiburg

Accessible online at:

www.karger.com/fok 


\section{Identifying Your Research Interests in CAM}

A mapping of postgraduate research activity in UK universities has been carried out over the last 2 years by the Research Council for Complementary Medicine (RCCM) (www.rccm. org.uk/) using an electronic survey targeted to universities $[1,2]$ An up-to-date mapping will be available on its new website early in 2011. A more comprehensive update carried out in 2010 also included a comprehensive search of $w w w$. theses.com and identified 81 out of 115 different UK universities registered with Universities UK ( $w w w$.universitiesuk.ac.uk/) that either currently, or have in the past supported CAM postgraduate students, $70 \%$ of all UK universities having supported at least one PhD student's CAM research. Of the 250 postgraduate studies identified, acupuncture was the most common subject of study ( $22 \%)$ followed by herbal medicine (16\%), homeopathy $(11 \%)$, and mindfulness $(9 \%)$. Research was located in a variety of departments such as nursing, anthropology, social care, psychology, health service, and CAM research units. A wide range of study designs has been incorporated into the research.

Trends suggest a real growth in CAM research over the last 10 years. Will this trend continue, given the potential reductions in research funding? The RCCM research has dem- onstrated that currently, one third of students are also CAM practitioners. It is encouraging that practitioners are becoming involved in shaping and influencing the research agenda. This increase in research may partially be due to research training, which has become part of UK CAM practitioner courses, as well as to the fact that many CAM professional bodies in the UK have recognised the important need to be able to demonstrate evidence of effectiveness.

This mapping project is of interest to the European Chapter as we particularly aim to identify research activity and specialist areas of interest in order to enhance opportunities for multidisciplinary research collaborations and future EU funding bids. The European Chapter hopes to develop special interest groups with specific research focuses and harness and to further build on its research capacity. Please help us develop our network by completing the short survey you can find at www.surveymonkey.com/s/S2HB9NL.

\section{References}

1 Robinson N, Lewith G: The RCCM 2008 Survey: Mapping doctoral and postgraduate CAM research in the United Kingdom. eCAM 2009, doi:10.1093/ecam/ nep184

Lewith G, Robinson N: CAM: Is any research worthwhile? What do the public want and how it may be delivered safely and effectively? J Royal Soc Med 2009;102: 411-414. 